\title{
Echocardiographic Findings in Children with Chronic Kidney Disease as Seen in the Resource -Limited Setting
}

Daberchi Kenneth Adiele, Henrietta Uchenna Okafor, Ngozi Chinyelu Ojinnaka, Basden Jones C Onwubere, Odutola Israel Odetunde ${ }^{\star}$ and Samuel Nkachukwu Uwaezuoke

Department of Pediatrics, University of Nigeria Teaching Hospital, Ituku-Ozalla, Enugu, Nigeria

*Corresponding author: Odetuunde Odutola Israel, Pediatric Nephrology Unit, Department of Pediatrics, University of Nigeria Teaching Hospital, Ituku-Ozalla, Enugu, Nigeria, Tel: +2348033348242; E-mail: odetoyintola@yahoo.co.uk

Rec date: Mar 10, 2014, Acc date: Apr 24, 2014, Pub date: Apr 29, 2014

Copyright: (C) 2014 Adiele DK, et al. This is an open-access article distributed under the terms of the Creative Commons Attribution License, which permits unrestricted use, distribution, and reproduction in any medium, provided the original author and source are credited.

\begin{abstract}
Background: Echocardiographic detectable cardiac abnormalities were studied to provide a platform for future longitudinal and interventional studies of children with Chronic Kidney Disease (CKD) in the south- east region of Nigeria.

Methods: A cross-sectional study of echocardiographic screening of children aged between 6 and 17 years with CKD and selected age and sex matched controls that were consecutively enrolled from the Pediatric nephrology clinic of the University of Nigeria Teaching Hospital (UNTH), Enugu, Nigeria.

Results: 9,419 patients within the age group 6-17 years who were seen at UNTH during the period of the study, 24 had CKD, giving an incidence of approximately 5 new cases per million-child population per year and a prevalence of 18.4 per million children population with a mean age of $12.33+4.24$ years. Lower mean ejection fraction (EFrac\%) values and E/A (transmitral flow velocity ratio) ratio were documented in patients compared to controls $(p<0.01)$. Echocardiographic detectable cardiac abnormalities occurred in $22(91.7 \%)$ of the patients and in $4(16.7 \%)$ of the controls $(p<0.01)$. The most common abnormality was left ventricular hypertrophy in 12 patients $(50.0 \%)$ with $8(66.6 \%)$ of 12 children having eccentric and $4(33.3 \%)$ having concentric hypertrophy.
\end{abstract}

Conclusions: This study shows that echocardiographic detectable cardiac abnormalities in children with CKD in the sub-region, is comparable to that of the other parts of the world with eccentric hypertrophy being more prevalent than concentric hypertrophy.

Keywords: Chronic kidney disease; Children; Echocardiogram; Cardiac abnormalities; Nigeria

\section{Introduction}

Chronic Kidney Disease (CKD) is a multi-systemic clinical condition characterized by an irreversible deterioration of renal function that gradually progresses to end-stage renal disease (ESRD). CKD is common in children older than 6 years and now poses a serious public health challenge with increasing incidence in children, threatening to reach epidemic proportion over the next decade [1,2].

Worldwide, and especially in developed countries, CKD is a growing problem, with the associated cardiovascular disease contributing largely to the mortality $[3,4]$. Most of the patients in subSaharan Africa and other developing countries die because of lack of treatment for both $\mathrm{CKD}$ and the associated cardiovascular abnormalities $[5,6]$. Mortality is about 30 times higher in patients with CKD than age matched population, contributed mainly by cardiovascular factors with higher figures from Africa [5-7]. Mortality rates remain significantly lower in children with ESRD compared with their adult with CKD [6]. Nevertheless, an assessment of the causes of death reflects the excess risk of cardiac and vascular disease and the high prevalence of left ventricular hypertrophy and dyslipidemia among children treated with renal replacement therapy $[8,9]$. Cardiovascular complications, with significant 2- dimensional echocardiographic (2D-ECHO) changes, have been shown by several studies to be a major cause of morbidity and mortality in CKD patients especially those on dialysis and post kidney transplant $[10,11]$ (Figure 1).

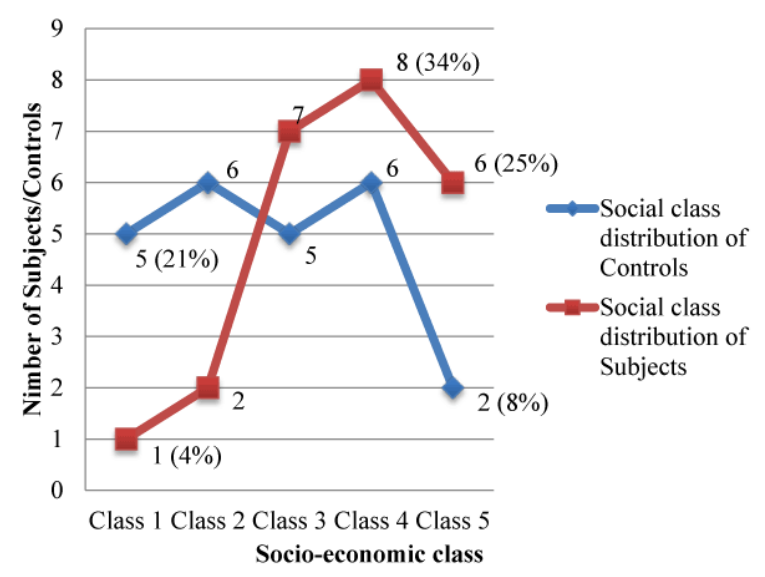

Figure 1: Social class distribution of study population. 
Cardiovascular disease often begins much earlier before ESRD sets in and patients with reduced kidney function are more likely to die of this cardiovascular disease [4]. There is paucity of local studies on cardiovascular abnormalities in children with CKD in the sub- region. The extents to which cardiovascular abnormalities affect Nigerian children with CKD as well as effect of its associated risk factors have not been explored. This study was thus initiated to form a platform for future longitudinal and interventional studies on children with CKD in this part of the world.

\section{Materials and Methods}

\section{Study area}

The study was carried out at the Pediatric Nephrology Clinic of the Children Out-Patient department (CHOP) and the Echocardiography room of the University of Nigeria Teaching Hospital (UNTH), ItukuOzalla, Enugu, South-East, Nigeria. The hospital serves as a major referral Centre to the surrounding health facilities in the SouthEastern Nigeria and beyond. The Pediatric Nephrology clinic of UNTH offers services to patients from the catchment area of the hospital which is predominantly Enugu and its environs in, SouthEast Nigeria with a population of 3.3 million $(3,267,837)$ and children constitute $40 \%$ of the population [12]. All children with features of renal disorder are referred to the pediatric nephrology clinic.

Ethical Clearance was obtained from the Independent Hospital Research and Ethical Committee (IHREC) of the UNTH and written informed consent and assent obtained from parents and patients where applicable.

\section{Study design}

This was a cross-sectional study of children aged between 6 and 17 years with history, physical findings and laboratory/imaging findings suggestive of kidney disease lasting up to 3 months without any clinical features suggestive of primary cardiovascular disease (both congenital and acquired) and selected age and sex matched controls who were enrolled consecutively for the study.

\section{Patient recruitment}

A screening urinalysis, using the reagent strip Medi-Combi 10 test strips manufactured by Machery-Nagel D-52313 Duren, Germany, was done for the controls while the patients were patients with clinical, laboratory features and diagnosis of CKD attending the renal clinic. CKD was defined as one or all of the following: past or present history of clinical markers of kidney damage like persistent abnormal urinalysis findings (proteinuria of $\geq 1+$; haematuria- microscopic or gross; red blood cell casts and granular casts on microscopy) or imaging for $>3$ months with evidence of structural and functional abnormalities, with or without decreased glomerular filtration rate (GFR), or GFR $<60 \mathrm{mls} / \mathrm{min} / 1.73 \mathrm{~m} 2$ for $\geq 3$ months, with or without kidney damage. However, for the controls, a normal urinalysis with absence structural and functional renal abnormalities was required. For both groups a comprehensive physical examination was done to exclude overt cardiovascular abnormalities. Study patients were selected after obtaining written informed consent. Laboratory investigation done study patients and controls included the following: blood urea, serum electrolytes, and creatinine; haemoglobin level; and haemoglobin genotyping. The eGFR was calculated for each of the patient and control using the modified Schwartz formula [13]. A trans-thoracic two-dimensional, M-mode, pulsed-wave, continuouswave and colour-flow Doppler echocardiography using SONOSCAPE SSI-5000, 2007 model with $3.5 \mathrm{~Hz}$ transducer probe, was done with the patients lying on the left lateral position. After two dimensional studies and M-mode measurements, left ventricular mass (LVM) was calculated using the anatomically validated formula: $\operatorname{LVM}(\mathrm{gm})=1.05$ (specific gravity of ventricular muscle) $\mathrm{X}$ \{[Left ventricular enddiastolic dimension (LVEDd) + Left ventricular posterior wall thickness ( LVPW) +Inter- ventricular septal thickness ( IVS)] 3 - Left ventricular end- diastolic dimension (LVEDd)3\}.

Left ventricular mass index (LVMI) was calculated by dividing the left ventricular mass (LVM) by the body surface area (BSA) and relative wall thickness (RWT) as $\mathrm{PW} /(\mathrm{LVEDd} / 2)$. Left ventricular hypertrophy was defined in absolute terms in children as LVMI $\geq 124.21 \mathrm{~g} / \mathrm{m} 2$ for both males and females, and increased RWT if $\geq$ 0.45 . Eccentric left ventricular hypertrophy: Presents with high LVMI and low RWT $(<0.45)$, with dilated internal ventricular dimensions; Concentric left ventricular hypertrophy: Presents with high LVMI and high RWT $(>0.45)$. In this case, wall thickness is increased in the presence of normal internal ventricular diameter. It is more associated with increased incidence of cardiovascular events; while Concentric Remodeling presents with high RWT and normal LVMI.

Trans-mitral early diastolic (E) and late diastolic (A) wave peaks were obtained, as well as the isovolumic relaxation time (IVRT) and Ewave deceleration time (DT), which were obtained using the pulsedwave Doppler and each of these could be used in assessing left ventricular diastolic function. E/A ratio less than 1.2 signifies left ventricular diastolic dysfunction.

The left ventricular systolic function was assessed using the ejection fraction and the fractional shortening. Once the IVS, LVEDd, LVESd and the LVPW measurements were taken on the M-mode, the echocardiography machine automatically generated these parameters: EFrac(\%), FS(\%), LVEDV, LVESV and SV. The values of LA dimension and aortic root dimension (Ao) were again measured directly on the M-mode by placing the cursor obliquely across the aortic root and the left atrium on the parasternal long-axis view of 2DEcho. Left ventricular mass (LVM) and left ventricular mass index (LVMI) were calculated manually by substituting all the measured parameters in there formulae.

Further analysis of the echocardiography measurements to determine specific abnormalities like left atrial dilatation (LAD), left ventricular dilatation (LVD), increased aortic root diameter for age and sex were done with the aid of a normograph on M-mode echocardiographic measurements on healthy infants and children by Kampmann et al. [14] Doppler and colour flow mapping were used to diagnose valve incompetence and grade the degree of regurgitation or stenosis. Patients with detected cardiovascular abnormalities from the study were followed up at the Pediatric Cardiology and Pediatric Nephrology units of the hospital. The observed associated factors for the cardiovascular abnormalities were re-evaluated at intervals and maintained at normal or near normal values as possible. They were also enrolled for interval echocardiography reviews.

\section{Data Analysis}

The data collected was analyzed using the statistical package for social sciences (SPSS) version 17. Simple frequencies and proportions (percentages) were used for comparison of demographic data. Student's t-test was used to compare pairs of means of parametric 
Citation: Adiele DK, Okafor HU, Ojinnaka NC, Onwubere BJ, Odetunde Ol, et al. (2014) Echocardiographic Findings in Children with Chronic

Page 3 of 6

variables like left ventricular end-diastole dimension (LVEDd) and other M-mode measurements between the study and control groups. Frequencies of non-parametric variables like left ventricular hypertrophy (LVH), left ventricular diastolic dysfunction etc were compared between the patients and controls using Chi-squared test corrected by Yates' method where necessary. Level of significance was regarded as less than $0.05(<0.05)$ at $95 \%$ confidence interval.

\section{Results}

During the six-month period of the study, nine thousand, four hundred and nineteen $(9,419)$ pediatric patients within the age group 6-17 years were seen at UNTH Children Emergency (CHER) and all the Pediatric Outpatient Clinics of the University of Nigeria Teaching Hospital, Ituku-Ozalla, Enugu, with twenty-four (24) cases of CKD seen, giving an incidence of approximately five (5) new cases per million-child population per year and the prevalence of 18.4 per million children populations with the mean age of $12.33+4.24$ years. There were 16 males and 8 females in both study and control groups, with male to female ratio of 2:1 (Table 1). Twenty- one $(87.5 \%)$ of the patients were in socieconomic class 3 to 5 while all the controls were of socieconomic class 1 to 4 . At enrollment, nine (37.5\%) patients were in stage I CKD, $4(16.7 \%)$ were in stage 5 while $2(8.3 \%)$ were in stage 3 (Table 2).

\begin{tabular}{|l|l|l|l|l|l|l|}
\hline \multirow{2}{*}{$\begin{array}{l}\text { Age } \\
\begin{array}{l}\text { Range } \\
\text { (Years }\end{array}\end{array}$} & \multicolumn{5}{|l|}{ Patient Control } \\
\cline { 2 - 7 } & $\begin{array}{l}\text { Male } \\
\mathbf{n}(\%)\end{array}$ & $\begin{array}{l}\text { Female } \\
\mathbf{n}(\%)\end{array}$ & $\begin{array}{l}\text { Total } \\
\mathbf{n}(\%)\end{array}$ & $\begin{array}{l}\text { Male } \\
\mathbf{n}(\%)\end{array}$ & $\begin{array}{l}\text { Female } \\
\mathbf{n}(\%)\end{array}$ & $\begin{array}{l}\text { Total } \\
\mathbf{n}(\%)\end{array}$ \\
\hline $6-8$ & $2(8.3) 5$ & $(20.7)$ & $7(29.1)$ & $2(8.3)$ & $5(20.7)$ & $7(29.1)$ \\
\hline $9-11$ & $2(8.3)$ & $1(4.2)$ & $3(12.5)$ & $2(8.3)$ & $1(4.2)$ & $3(12.5)$ \\
\hline $12-14$ & $3(12.5)$ & $1(4.2)$ & $4(16.7)$ & $3(12.5)$ & $1(4.2)$ & $4(16.7)$ \\
\hline $15-17$ & $9(37.5)$ & $1(4.2)$ & $10(41.7)$ & $9(37.5)$ & $1(4.2)$ & $10(41.7)$ \\
\hline TOTAL & $\begin{array}{l}16 \\
(66.7)\end{array}$ & $8(33.3)$ & $\begin{array}{l}24 \\
(100.0)\end{array}$ & $16(66.7)$ & $8(33.3)$ & $24(100.0)$ \\
\hline
\end{tabular}

Table 1: Age and Sex Distribution of Patients and Controls

\begin{tabular}{|c|c|c|c|c|}
\hline \multirow{2}{*}{$\begin{array}{l}\text { Stages of } \\
\text { CKD }\end{array}$} & \multicolumn{4}{|c|}{ Age group (in years) } \\
\hline & $\begin{array}{l}6-8 \\
n\end{array}$ & $\begin{array}{l}9-11 \\
n\end{array}$ & $\begin{array}{l}12-14 \\
n\end{array}$ & $\begin{array}{l}15-17 \\
n\end{array}$ \\
\hline stage 1 & 2 & 1 & 1 & 5 \\
\hline stage 2 & 2 & 2 & 1 & 1 \\
\hline stage 3 & 2 & 0 & 0 & 0 \\
\hline stage 4 & 0 & 0 & 2 & 1 \\
\hline stage 5 & 1 & 0 & 0 & 3 \\
\hline TOTAL & 7 & 3 & 4 & 10 \\
\hline
\end{tabular}

Table 2: Distribution of CKD stages for Age in Patients

$$
\chi^{2} y=0.08, p=0.78 ; \mathrm{df}=1
$$

The mean values of LVESV, IVS, LVPW, LVM, LVMI, RWT, Awave velocity, Ejection fraction (EFrac\%) and E/A for patients and controls as shown in the Table $3 \mathrm{~A} \& \mathrm{~B}$.

A total of eleven (11) echocardiographic abnormalities were identified in the study population. The distribution of these abnormalities in patients and controls is shown in Table 4.

Doppler studies revealed functional (non-pathological) valvular regurgitation for all four different heart valves in 9 (37.5\%) of the patients and for only pulmonary valve in 9 (37.5\%) of controls as shown in Table 5. Two (8.3\%) of the patients with functional valvular regurgitation had mitral involvement, 3 (12.5\%) tricuspid and $1(4.2 \%)$ aortic. Eight (33.3\%) of patients and 9(37.5\%) of controls had functional pulmonary valvular regurgitation. Five (55.6\%) of the affected patients had multiple valvular regurgitation. Nine $(37.5 \%)$ patients and 9 (37.5\%) controls had one form of functional valvular regurgitation or the other. On the other hand, pathological grade 4 mitral valve regurgitation was noted in another $2(8.3 \%)$ patients with Vmax $250 \mathrm{~cm} / \mathrm{sec}$, PG $25 \mathrm{mmHg}$ and Vmax $274 \mathrm{~cm} / \mathrm{sec}$, PG 30mmHg in the respective patients (Table 5 ).

\begin{tabular}{|l|l|l|l|l|}
\hline $\begin{array}{l}\text { Parameter } \\
\text { (unit) }\end{array}$ & $\begin{array}{l}\text { PATIENTS } \\
\text { Mean } \pm \text { 2SD } \\
{[\mathbf{n}=\mathbf{2 4}]}\end{array}$ & $\begin{array}{l}\text { CONTROLS } \\
\text { Mean } \pm \text { 2SD } \\
{[\mathbf{n}=\mathbf{2 4}]}\end{array}$ & t-value & p-value \\
\hline Ao (cm) & $2.57 \pm 0.52$ & $2.56 \pm 0.42$ & 0.10 & 0.93 \\
\hline LVESd (cm) & $3.19 \pm 0.90$ & $2.77 \pm 0.60$ & 1.89 & 0.07 \\
\hline LVEDd (cm) & $4.77 \pm 0.86$ & $4.66 \pm 0.74$ & 0.48 & 0.63 \\
\hline LAd (cm) & $3.39 \pm 0.77$ & $3.13 \pm 0.49$ & 1.42 & 0.16 \\
\hline FS (\%) & $37.17 \pm 12.35$ & $40.13 \pm 6.77$ & 1.03 & 0.31 \\
\hline LVEDV (mls) & $122.69 \pm 59.14$ & $111.76 \pm 46.69$ & 0.71 & 0.48 \\
\hline LVESV (mls) & $41.47 \pm 30.71$ & $27.14 \pm 13.31$ & 2.10 & $0.04^{*}$ \\
\hline SV (mls) & $74.37 \pm 33.77$ & $84.62 \pm 37.40$ & 1.00 & 0.33 \\
\hline EFrac (\%) & $65.58 \pm 12.14$ & $75.75 \pm 7.23$ & 3.53 & $<0.01^{*}$ \\
\hline
\end{tabular}

Table 3A: Echocardiographic Measurements of Patients and Controls. [M-mode echo]

\begin{tabular}{|l|l|l|l|l|}
\hline $\begin{array}{l}\text { Parameter } \\
\text { (unit) }\end{array}$ & $\begin{array}{l}\text { PATIENTS } \\
\text { Mean } \pm \text { 2SD } \\
{[\mathbf{n = 2 4 ]}}\end{array}$ & $\begin{array}{l}\text { CONTROLS } \\
\text { Mean } \pm \text { 2SD } \\
{[\mathbf{n}=\mathbf{2 4}]}\end{array}$ & t-value & p-value \\
\hline IVS (cm) & $0.83 \pm 0.36$ & $0.61 \pm 0.16$ & 2.68 & $0.01^{*}$ \\
\hline LVPW (cm) & $0.85 \pm 0.25$ & $0.65 \pm 0.11$ & 3.65 & $<0.01^{*}$ \\
\hline LVM $(\mathbf{g m})$ & $176.43 \pm 94.23$ & $117.37 \pm 50.08$ & 2.70 & $0.01^{*}$ \\
\hline LVMI (gm/m) $)$ & $138.09 \pm 64.06$ & $83.45 \pm 16.63$ & 4.04 & $<0.01^{*}$ \\
\hline RWT (cm/cm) & $0.4033 \pm 0.24$ & $0.2842 \pm 0.06$ & 2.38 & $0.02^{*}$ \\
\hline IVRT (sec) & $0.08 \pm 0.03$ & $0.07 \pm 0.01$ & 1.48 & 0.15 \\
\hline DT (sec) & $0.15 \pm 0.05$ & $0.14 \pm 0.04$ & 0.80 & 0.44 \\
\hline E (cm/sec) & $84.19 \pm 18.17$ & $88.90 \pm 12.73$ & 1.04 & 0.30 \\
\hline A (cm/sec) & $60.91 \pm 25.39$ & $45.90 \pm 9.59$ & 2.71 & $0.01^{*}$ \\
\hline
\end{tabular}


Citation: Adiele DK, Okafor HU, Ojinnaka NC, Onwubere BJ, Odetunde Ol, et al. (2014) Echocardiographic Findings in Children with Chronic Kidney Disease as Seen in the Resource -Limited Setting. J Nephrol Ther 4: 158. doi:10.4172/2161-0959.1000158

Page 4 of 6

\begin{tabular}{|l|l|l|l|l|}
\hline E/A ratio & $1.58 \pm 0.67$ & $2.02 \pm 0.42$ & 2.73 & $0.01^{*}$ \\
\hline
\end{tabular}

Table 3B: Echocardiography Measurements of Patients and Controls [M-mode echo]

$$
\text { * }=\text { Significant }
$$

\begin{tabular}{|c|c|c|c|c|}
\hline $\begin{array}{l}\text { Echo Cardiovascular } \\
\text { Abnormality }\end{array}$ & $\begin{array}{l}\text { PATIENTS } \\
\text { n (\%) }\end{array}$ & $\begin{array}{l}\text { CONTROLS } \\
n(\%)\end{array}$ & $x y 2$ & $\begin{array}{l}\mathrm{p}- \\
\text { value }\end{array}$ \\
\hline Left Atrial Dilatation (LAD) & $11(45.8)$ & $2(8.3)$ & 6.75 & $0.01^{*}$ \\
\hline $\begin{array}{l}\text { Left Ventricular Dilatation } \\
\text { (LVD) }\end{array}$ & $10(41.7)$ & $1(4.2)$ & 7.55 & $0.01^{*}$ \\
\hline LV Systolic dysfunction & $2(8.3)$ & $0(0.0)$ & 0.52 & 0.47 \\
\hline LV Diastolic dysfunction & $9(37.5)$ & $0(0.0)$ & 8.75 & $<0.01^{*}$ \\
\hline Increased aortic root diameter & $7(29.2)$ & $2(8.3)$ & 2.19 & 0.14 \\
\hline $\begin{array}{l}\text { Left Ventricular hypertrophy } \\
\text { (LVH) } \\
\text { Concentric LVH } \\
\text { Eccentric LVH } \\
\text { Concentric remodeling }\end{array}$ & $\begin{array}{l}12(50.0) \\
4(16.7) \\
8(33.3) \\
3(12.5)\end{array}$ & $\begin{array}{l}0(0.0) \\
0(0.0) \\
0(0.0) \\
0(0.0)\end{array}$ & $\begin{array}{l}13.4 \\
4 \\
2.46 \\
7.35 \\
1.42\end{array}$ & $\begin{array}{l}<0.01^{*} \\
0.12 \\
0.01^{*} \\
0.23\end{array}$ \\
\hline Thickened Mitral valve leaflets & $3(12.5)$ & $0(0.0)$ & 1.42 & 0.23 \\
\hline $\begin{array}{l}\text { Thickened Tricuspid valve } \\
\text { leaflets }\end{array}$ & $3(12.5)$ & $0(0.0)$ & 1.42 & 0.23 \\
\hline Thickened Aortic valve cusps & $1(4.2)$ & $0(0.0)$ & 0.00 & 1.00 \\
\hline Thickened Pericardium & $3(12.5)$ & $0(0.0)$ & 1.42 & 0.23 \\
\hline Pericardial effusion & $4(16.7)$ & $0(0.0)$ & 2.46 & 0.12 \\
\hline
\end{tabular}

Table 4: Comparison of Echocardiographic Findings detected amongst Patients and Controls [2-D Echo]

$$
{ }^{*}=\text { Significant }
$$

\begin{tabular}{|l|l|l|l|l|}
\hline Valve Incompetence & $\begin{array}{l}\text { PATIENT } \\
\mathbf{n}(\%) \mathbf{n}^{\prime}=\mathbf{9}\end{array}$ & $\begin{array}{l}\text { CONTROL } \\
\mathbf{n}(\%) \mathbf{n}^{\prime}=\mathbf{9}\end{array}$ & $\mathrm{x}$ y 2 & p-value \\
\hline Mitral (MI) & $2(8.3)$ & $0(0.0)$ & 0.52 & 0.47 \\
\hline Aortic (Al) & $1(4.2)$ & $0(0.0)$ & 0.00 & 1.00 \\
\hline Tricuspid (TI) & $3(12.5)$ & $0(0.0)$ & 1.42 & 0.23 \\
\hline Pulmonary (PI) & $8(33.3)$ & $9(37.5)$ & 0.00 & 1.00 \\
\hline
\end{tabular}

Table 5: Distribution of Functional (Non-Pathologic) Valvular Regurgitation (Incompetence) in Patients and Controls. [DOPPLER]

\section{Discussion}

The overall case incidence rate of CKD in children aged 6-17 years in this study was five (5) new cases per million-child population per year and the prevalence of 18.4 per million age-related populations (MARP). This value is comparable to 14.9 per MARP reported by Odetunde et al. in the earlier study done in the same center [15]. The prevalence obtained in this study is lower compare to the reports from Chilean survey of 42.5 per MARP [16] Jordan report of 51 per MARP

[1,17], Italian Italkid project of 74.7 per MARP [18] and United States renal data system (USRDS) report of 82 per MARP 1,7 and could be explained by the fact that these studies were extensively done to obtain data all over the index country from both the hospital-based and outright population-based studies with wide spread coverage giving a better representation of the country's population unlike the skewed coverage of this hospital-based study.

The echocardiographic abnormalities detected in children with CKD in this study are in keeping with those reported by other workers who studied similar aged- group of patients $[11,19,20]$. Left ventricular hypertrophy (LVH) was noted in this study to be the most common cardiac abnormality and tends to develop early in the disease and cuts across all the stages of CKD $(\mathrm{p}<0.01)$. The findings in this study is in keeping with previous reports that documented $\mathrm{LVH}$ as the most common cardiovascular abnormality in children with CKD $[11,19,20]$. The specific LVH prevalence documented in this study is similar to the reports by Nashwa et al. in similar group of patients in Australia [21] and El-Husseini et al. in post- transplant patients in Egypt [22]. However, this $\mathrm{LVH}$ prevalence rate is higher compared to $16-31 \%$ reported in similar groups of patients by some authors from Cincinnati, United States of America and Canada [23-25]. The relatively high prevalence rate of LVH in this study could be attributed to factors such as poor standard of health services, low level of health awareness, drug abuse and use of herbal concoctions, poor healthseeking behavior and extreme poverty, all of which could be a contributor to the late presentation and late initiation of appropriate therapy seen amongst most of the patients with CKD in the subregion. Most of the cases that present late are often complicated with fluid over-load, which further increase the risk of LVH [24].

In this study, eccentric left ventricular hypertrophy was predominant $(33.3 \%)$ compared to concentric left ventricular hypertrophy $(16.7 \%)$ caused by hypertension, signifying that volume overload with high cardiac output is a major factor in Nigerian children with CKD. This is observed as most of the patients were extremely edematous, with some having symptoms of pulmonary edema like cough and breathlessness at the time of presentation. This finding could further be attributed to lower rate of dialysis and ultrafiltration obtained by children with CKD in the sub region when compared to their counterparts in the developed countries of the world like Europe and America. Eccentric left ventricular hypertrophy as seen in the patients is supported by Weaver et al. [24] who noted a positive association between LV mass index (LVMI) and cardiac output in children with CKD in United States of America.

On the other hand concentric left ventricular hypertrophy, which occurs due to excessive pressure (hypertension) on the ventricular muscles, as seen in fewer (16.7\%) patients has been associated with increased incidence of cardiac ischemia and sudden death $[3,26,27]$. There are varying reports as to whether eccentric or concentric LVH is more common in children $[20,24,28]$. Generally, reports from the developed part of the world show more of concentric hypertrophy $[20,24]$ which could be because they can afford chronic dialysis and ultra-filtration with resultant marked reduction in volume overload. This is not an absolute finding as other authors in Europe and America documented predominance of eccentric LVH [22,28,29].

Left atrial dilatation (LAD) and left ventricular dilatation (LVD) noted in this study as the second and third most common cardiovascular abnormalities respectively was similar to the reports of Parekh et al. in the USA and El-Husseini et al. in Egypt [22,30]. These dilated chambers could be attributed to state of hypervolemia observed 
in these patients, also resulting in eccentric enlargements. The left atrial size could be further increased in this group of patients if there are associated calcification changes especially of the mitral valve or annulus as seen commonly in patients with advanced CKD, who may or may not be on chronic dialysis. 20 Left ventricular dilatation if persistent and progressive could result in dilated cardiomyopathy and subsequent left ventricular pump failure (systolic dysfunction) as seen in $2(8.3 \%)$ patients.

The trend noted in this study of a higher prevalence of left ventricular diastolic dysfunction as against left ventricular systolic dysfunction is now a common finding in children with CKD. This has been observed by other studies [20,31,32]. This observation is in contrast to adults in whom left ventricular systolic dysfunction is more frequent and often associated with early cardiac failure and decreased survival [33]. The reason for this higher prevalence of diastolic dysfunction in children has been attributed to high levels of serum cystatin $\mathrm{C}$ and high left ventricular mass index in this group of children [34]. Furthermore, children with CKD are known to have decreased aerobic capacity even in early stages of the illness. Maximal aerobic capacity (VO2 max) represents the cardiovascular system's ability to take up, distribute, and utilize oxygen to perform work during maximal exercise. Lower VO2 max has also been shown to predict left ventricular diastolic dysfunction in this group of patients even in the phase of normal left ventricular systolic function [35-38] Abnormal left ventricular diastolic function in children is observed even with early to late transmitral flow velocity ratio (E/A) not being less than 1.0, [32,33] as the trans-mitral Doppler velocities in children are unfortunately affected by several factors including left atrial pressure and preload, [22] which is particularly important as most of the children with CKD are often hypervolemic.

This study noted various degrees of cardiac thickening (calcification) in the patients involving mitral valve, tricuspid valve and pericardium all at equal frequency, while the least affected was the aortic valve. These thickenings were noted to occur early in the course of $\mathrm{CKD}$ in these children. Contrary to earlier report that cardiovascular thickening (calcification) are not seen in less than twenty years of age, [36] recent studies with more sensitive methods of identifying these calcifications like magnetic resonant imaging (MRI), have shown that it is a burden even in the first decade of life in CKD patients.37This finding and sequence of involvement has been reported by other studies especially in adolescents [36,38-40].

The observation in this study of pericardial effusion occurring more than pericardial thickening is at variance with results of some other studies, $[40,41]$ including a study on adults in the same environment with the index study. However, a few other studies noted more of acute pericarditis with effusion than thickening in children, especially in those on haemodialysis $[23,42]$. It was documented that acute pericarditis and the resultant pericardial effusion is associated with uremia and hypervolemia, especially in patients with insufficient dialysis and ultra-filtration, as seen commonly among children with CKD in the West African sub region [15,43]. The pericardial effusion may occasionally be resistant to dialysis requiring surgical drainage $[23,42]$.

The high prevalence of non-pathologic pulmonic valve regurgitation noted in controls in this study is in agreement with the finding of Brand et al. who documented a similar prevalence of $21.9 \%$, with further demonstration of a significant increase with age [44]. Van Dijk et al. [45] even noted higher prevalence (84\%) of pulmonic regurgitation in normal children. In all the cases of functional (non- pathological) pulmonic regurgitation noted by Brand and Van Dijik and their co-workers, as well as noted in the controls of this study, there were no structural or haemodynamic abnormality observed. However, the pathological mitral valve regurgitation noted in two patients of this study may not have been documented earlier in children with CKD as the authors could not find any reported study in this group of children.

\section{Conclusion}

We conclude that children with CKD are prone to the development of cardiac dysfunctions in the early state of the disease and these calls for more studies in the sub-region. Early and regular echocardiographic studies of all children with CKD to detect early cardiac changes, institute interventions and follow-up are required. Primary prevention of CKD and its burden by intensifying principles of preventive nephrology, especially health education and the screening for microalbuminuria and proteinuria for children at risk and as routine outpatient/preschool entry investigations, which should be repeated at intervals, is strongly advocated.

\section{References}

1. Warady BA, Chadha V (2007) Chronic kidney disease in children: the global perspective. Pediatr Nephrol 22: 1999-2009.

2. Sanjeev G (2013) chronic kidney Disease. eMedicine specialties: paediatrics-general medicine-nephrology.

3. Groothoff JW, Gruppen MP, Offringa M, Hutten J, Lilien MR, et al. (2002) Mortality and causes of death of end-stage renal disease in children: a Dutch cohort study. Kidney Int 61: 621-629.

4. Chavers BM, Li S, Collins AJ, Herzog CA (2002) Cardiovascular disease in pediatric chronic dialysis patients. Kidney Int 62: 648-653.

5. Krzesinski JM, Sumaili KE, Cohen E (2007) How to tackle the avalanche of chronic kidney disease in sub-Saharan Africa: the situation in the Democratic Republic of Congo as an example. Nephrol Dial Transplant 22: 332-335.

6. Sumaili EK, Krzesinski JM, Zinga CV, Cohen EP, Delanaye P, et al (2009) Prevalence of chronic kidney disease in Kinshasa: results of a pilot study from the Democratic Republic of Congo. Nephrol Dial Transplant 24: $117-122$.

7. U.S. renal data system, USRDS 2007 (19th) Annual data report: Atlas of end-stage renal disease in the United States, National Institutes of Health, National Institute of Diabetes and Digestive and Kidney Diseases, Bethesda, MD.

8. Mitsnefes MM, Daniels SR, Schwartz SM, Meyer RA, Khoury P, et al (2000) Severe left ventricular hypertrophy in pediatric dialysis: prevalence and predictors. Pediatr Nephrol 14: 898-902.

9. Silverstein DM, Palmer J, Polinsky MS, Braas C, Conley SB, et al. (2000) Risk factors for hyperlipidemia in long-term pediatric renal transplant recipients. Pediatr Nephrol 14: 105-110.

10. Schaefer F (2008) Cardiac disease in children with mild-to-moderate chronic kidney disease. Curr Opin Nephrol Hypertens 17: 292-297.

11. Malikenas A, Cerniauskiene V, Jakutovic M, Jankauskiene A (2005) Left ventricular geometry in children with chronic renal failure. Medicina (Kaunas) 41 Suppl 1: 5-11.

12. Nigeria 2006 Census figures (Population)- Nigeria Masterweb. 2013.

13. Schwartz GJ, Muñoz A, Schneider MF, Mak RH, Kaskel F, et al. (2009) New equations to estimate GFR in children with CKD. J Am Soc Nephrol 20: 629-637.

14. Kampmann C, Wiethoff CM, Wenzel A, Stolz G, Betancor M, et al. (2000) Normal values of M mode echocardiographic measurements of more than 2000 healthy infants and children in central Europe. Heart 83: 667-672. 
Citation: $\quad$ Adiele DK, Okafor HU, Ojinnaka NC, Onwubere BJ, Odetunde Ol, et al. (2014) Echocardiographic Findings in Children with Chronic Kidney Disease as Seen in the Resource -Limited Setting. J Nephrol Ther 4: 158. doi:10.4172/2161-0959.1000158

Page 6 of 6

15. Odetunde OI, Okafor HU, Uwaezuoke SN, Ezeonwu BU, Adiele KD, et al. (2014) Chronic kidney disease in children as seen in a tertiary hospital in Enugu, South-East, Nigeria. Niger J Clin Pract 17: 196-200.

16. Lagomarsimo E, Valenzuela A, Cavagnaro F, Solar E (1999) Chronic renal failure in pediatrics 1996. Chilean survey. Pediatr Nephrol 13: 288-291.

17. Hamed RM (2002) The spectrum of chronic renal failure among Jordanian children. J Nephrol 15: 130-135.

18. Ardissino G, Daccò V, Testa S, Bonaudo R, Claris-Appiani A, et al. (2003) Epidemiology of chronic renal failure in children: data from the ItalKid project. Pediatrics 111: e382-387.

19. Maharaj S, Naidoo DP (2007) Chronic kidney disease and cardiovascular disease. CME J 25: 384-388.

20. Hüting J (1994) Mitral valve calcification as an index of left ventricular dysfunction in patients with end-stage renal disease on peritoneal dialysis. Chest 105: 383-388.

21. Nashwa MS, Bahia HM, Fatina IF (2009) Prevalence of viral infection among Egyptian children with end stage renal disease. Aust J Basic Appl Sci 3: 3479-3491.

22. El-Husseini AA, Sheashaa HA, Hassan NA, El-Demerdash FM, Sobh MA, et al. (2004) Echocardiographic changes and risk factors for left ventricular hypertrophy in children and adolescents after renal transplantation. Pediatr Transplant 8: 249-254.

23. Barberato SH, Pecoits-Filho R (2010) [Echocardiographic alterations in patients with chronic kidney failure undergoing hemodialysis]. Arq Bras Cardiol 94: 140-146.

24. Weaver DJ Jr, Kimball TR, Koury PR, Mitsnefes MM (2009) Cardiac output and associated left ventricular hypertrophy in pediatric chronic kidney disease. Pediatr Nephrol 24: 565-570.

25. Mitsnefes MM (2008) Cardiovascular complications of pediatric chronic kidney disease. Pediatr Nephrol 23: 27-39.

26. Whyte DA, Fine RN (2008) Chronic kidney disease in children. Pediatr Rev 29: 335-341.

27. Ritz E, Wanner C (2008) The challenge of sudden death in dialysis patients. Clin J Am Soc Nephrol 3: 920-929.

28. Mitsnefes MM (2005) Cardiovascular disease in children with chronic kidney disease. Adv Chronic Kidney Dis 12: 397-405.

29. Shroff $\mathrm{R}$ (2009) Monitoring cardiovascular risk factors in children on dialysis. Perit Dial Int 29 Suppl 2: S173-175.

30. Parekh RS, Carroll CE, Wolfe RA, Port FK (2002) Cardiovascular mortality in children and young adults with end-stage kidney disease. J Pediatr 141: 191-197.

31. Drozdz D, Kordon Z, Pietrzyk JA, Drozdz M, RudziÅ,ski A, et al. (2008) [The assessment of heart function in children with chronic kidney disease (CKD)]. Pol Merkur Lekarski 24 Suppl 4: 98-100.
32. Mitsnefes MM, Kimball TR, Border WL, Witt SA, Glascock BJ, et al. (2004) Impaired left ventricular diastolic function in children with chronic renal failure. Kidney Int 65: 1461-1466.

33. Johnstone LM, Jones CL, Grigg LE, Wilkinson JL, Walker RG, et al. (1996) Left ventricular abnormalities in children, adolescents and young adults with renal disease. Kidney Int 50: 998-1006.

34. Mitsnefes M, Kimbal T, Kartal J, Kathman T, Mishra J, et al. (2006) Serum cystatin $\mathrm{C}$ and left ventricular diastolic dysfunction in children with chronic kidney disease. Pediatr Nephrol 21: 1293-1298.

35. Weaver DJ Jr, Kimball TR, Knilans T, Mays W, Knecht SK, et al. (2008) Decreased maximal aerobic capacity in pediatric chronic kidney disease. J Am Soc Nephrol 19: 624-630.

36. Wilson AC, Mitsnefes MM (2009) Cardiovascular disease in CKD in children: update on risk factors, risk assessment, and management. Am J Kidney Dis 54: 345-360.

37. Goodman WG, London G, Amann K, Block GA, Giachelli C, et al. (2004) Vascular calcification in chronic kidney disease. Am J Kidney Dis 43: 572-579.

38. Civilibal M, Caliskan S, Adaletli I, Oflaz H, Sever L, et al. (2006) Coronary artery calcifications in children with end-stage renal disease. Pediatr Nephrol 21: 1426-1433.

39. Rufino M, García S, Jiménez A, Alvarez A, Miquel R, et al. (2003) Heart valve calcification and calcium $\mathrm{x}$ phosphorus product in hemodialysis patients: analysis of optimum values for its prevention. Kidney Int Suppl : S115-118.

40. Ijoma C, Arodiwe E, Ulasi I, Anisiuba B (2010) Pericardial thickening is a major cardiac complication in patients with chronic kidney disease at first presentation. Int Neprol 2: 438-446.

41. Nardi E, Palermo A, Cerasola G (2010) Pericardial thickening in chronic kidney disease; what meaning? Int Nephrol Urol 2: 586-587.

42. Gunukula SR, Spodick DH (2001) Pericardial disease in renal patients. Semin Nephrol 21: 52-56.

43. Michael IO, Gabreil OE (2004) Chronic renal failure in children of benin, Nigeria. Saudi J Kidney Dis Transpl 15: 79-83.

44. Brand A, Dollberg S, Keren A (1992) The prevalence of valvular regurgitation in children with structurally normal hearts: a color Doppler echocardiographic study. Am Heart J 123: 177-180.

45. Van Dijk AP, Van Oort AM, Daniëls O (1994) Right-sided valvular regurgitation in normal children determined by combined colour-coded and continuous-wave Doppler echocardiography. Acta Paediatr 83: 200-203.
This article was originally published in a special issue, entitled: "Pediatric Nephrology", Edited by Dr. Moazzam Hossain, Bangabandhu Sheikh Mujib Medical University, Bangladesh 